\title{
Stroke and gender identity in teacher success: from learners' viewpoints
}

\author{
Zahra Noorbakhsh, Reza Pishghadam* and Fahime Saboori \\ Department of English Language, Ferdowsi University of Mashhad, Iran.
}

\begin{abstract}
The purpose of the present study was to explore the roles of teacher gender identity and stroke in teacher success. All variables were viewed from the learners' viewpoints. Three scales were used to measure stroke, teacher gender identity and teacher success. The participants consisted of 287 English learners in private language institutes. To analyse the data, first Pearson product-moment correlation was used, the results of which revealed significant relationships among all these variables. Next, Path Analysis was employed to examine the predictive power of teacher gender identity and stroke in teacher success. The findings indicated that femininity and masculinity predicted stroke and that stroke and androgyny were positive predictors of teacher success.
\end{abstract}

Keywords: Teacher success, gender identity, stroke.

\section{INTRODUCTION}

As a result of today's growth of international relations and the extended interest in technology and science, the need to learn English as an international language is more evident than the past. Lack of enough resources, little contact with the target language, and limited number of native speakers give the teachers of English as a foreign language (EFL) an outstanding role and importance. While teacher education programmes have done their best to identify how to produce successful teachers, there is still a debate whether teaching is an art or a science. Therefore, an extensive portion of language education research has addressed the characteristics of successful language teachers. "Teacher success" or "teacher effectiveness" can be defined in several ways because of its multifaceted nature (Pishghadam, Baghaei et al., 2011). Papanastasiou (1999: p.6) stated, "No single teacher attribute or characteristic is adequate to define an effective teacher".

To keep in line with developments in psychology and cognitive science, there is an upsurge in language education research to investigate the impact of language teachers'cognitive, affective and personality characteristic on their teaching practices and success. Among those investigated, the most prominent ones include EFL teachers' multiple intelligences (Pishghadam \& Moafian, 2008), emotional intelligence (Hashemi, 2008), selfefficacy (Moor \& Esselman, 1992; Muijs \& Rejnolds, 2001), teachers' creativity (Pisghadam et al., 2012), the use of NLP (Neurolinguistic Programming) techniques (Pishgadam, Shayesteh et al., 2011), personality traits (Elizabeth et al., 2007; Pishghadam, Shayesteh et al., 2011), narrative intelligence (Pishghadam et al., 2013), stroke analysis (Irajzad et al., 2017; Pishghadam \& Khajavy, 2014) and contextualisation-emotionalisation (Pishghadam, Shayesteh et al., 2016).

In the same vein, the concept of femininity and masculinity may impact the quality of teaching and hence contribute to a more efficient teacher education. A person's perception of his/her own degree of maleness and femaleness regardless of his/her biological sex is referred to as gender identity or one's sense of femininity and masculinity (Bem, 1974). Different cultures and ethnic groups might have various gender roles (Harris, 1994). Generally speaking, males are assumed to be more assertive, tough and competitive in different societies, whereas women are more modest, caring and cooperative (Hofstede, 1980). As a person could be high or low in both masculinity and femininity at the same

"Corresponding author (pishghadam@um.ac.ir; (iD https://orcid.org/0000-0001-6876-5139) 
time, Bem (1974) labeled the gender identity of those who possess both masculine and feminine qualities, depending on which behaviors best suit a particular situation, as androgynous. As for educational settings, while feminine teachers seem to be more permissive, promote cooperation and value rapport in their teaching practices, masculine ones are more assertive, corrective and concerned with the excellence of the students.

Another influential factor in teacher success might be stroke. There have been a number of studies on the important role of stroke in educational systems (Irajzad, 2015; Pishghadam \& Khajavy, 2014; Yazdanpour, 2015). Shirai (2006) defines stroke as every action which might acknowledge other's presence and values. In addition, stroke, as a unit of human recognition, can satisfy an individual's need for recognition (Berne, 1988). Giving and receiving strokes will help people in maintaining their motivation and also stimulating other people's motivation (Freedman, 1993; Kusluvan, 2003). Research has shown that positive strokes, given by the teachers, can increase students' motivation and lead them toward having higher levels of performance (Pishghadam \& Khajavy, 2014).

Extensive research has been carried out up to now to explore traits of successful teachers (e.g., Pishghadam, Baghaei et al., 2011; Pishghadam \& Moafian, 2008; Richardson, 2001), but the roles of stroke and teachers' gender identity have received scant attention. As these two concepts have the potential of enriching teacher education, especially for EFL teachers, and leading to insightful educational implications, this paper seeks to investigate their relationship with teacher success.

\section{LITERATURE REVIEW}

\section{Stroke}

Teachers' positive relationship with students can motivate students, and help them build the necessary interpersonal skills (Pierson, 2003). These interpersonal relationships can be examined with the help of a theory proposed by Eric Berne known as Transactional Analysis (TA) theory (Stewart \& Joines, 1987). "TA is a theory of personality and psychotherapy for personal growth and personal change" (Stewart \& Joines, 1987: p. 3). TA helps teachers and students have clear and productive interactions in the educational contexts (Stewart \& Joines, 1987). Six basic components of TA theory are: ego states, life positions, life scenario, transactions, time structures and strokes (Berne, 1988; Shirai, 2006). According to Shirai (2006), stroke refers to every action to acknowledge other's presence and values. Berne (1988) defined stroke as a unit of human recognition that can satisfy an individual's need for recognition. He believed that all human beings are in need of being acknowledged by others and this need is satisfied through receiving strokes.

Different types of stroke are verbal/non-verbal, positive/negative and conditional/unconditional (Stewart \& Joines, 1987). While verbal strokes involve an exchange of spoken words, non-verbal strokes involve some actions such as nodding without any spoken word. Positive strokes (e.g., I love you) are perceived as pleasant and satisfactory by the receivers while negative strokes (e.g., I hate you) are unpleasant to the receivers and make them feel dissatisfied. Conditional strokes (e.g., I like your dress; you are not a good singer) are about what people do while unconditional strokes (e.g., I love you; I hate you) refer to what people are (Stewart \& Joines, 1987). According to Solomon (2003), unconditional negative stroke can not only destroy a person's selfimage, but it might also seriously influence the way that person approaches life. Hence, teachers must be careful not to give this type of stroke in the classroom.

It has been suggested that "... negative strokes are better than no strokes at all" (Solomon, 2003: p. 19). If there is no positive stroke to be received, the people will search for negative strokes to satisfy their needs for strokes. Obviously, positive strokes are better and more advantageous for healthy mental development (Watchel, 1980). Stroking causes the reinforcement of the behavior which is noted (Stewart \& Joines, 1987). According to Freedman (1993), learners will achieve higher levels of performance in an environment which is stroke-rich (Freedman, 1993; Kusluvan, 2003). So, strokes can contribute to the success of the learners (Pishghadam \& Khajavy, 2014). There are different types of strokes recognising students' presence in the classroom, such as recalling students' names, providing them with feedback, giving them the opportunity to express themselves and encouraging them to think about their capabilities positively (Irajzad, 2015).

In a recent study, Pishghadam \& Khajavy (2014) developed and validated a Student Stroke Scale (SSS) for assessing the strokes students receive within the classrooms and demonstrated that stroke has a strong relationship with students' extrinsic and intrinsic motivation. When students receive high levels of positive stroke, they are more motivated to learn the English language. Moreover, Yazdanpour (2015) has constructed and validated a Teacher Stroke Scale and examined its relationship with teacher burnout. She showed that there is a negative relationship between teacher stroke and teacher burnout. Accordingly, the more strokes the teachers deliver, the lower their level of burnout will be. Irajzad (2015) has also shown that 
Iranian English school teachers achieved the second rank, after Arabic teachers, in providing students with strokes. She reported that English school teachers, in Iran, gave more strokes to their students than Persian and Arabic teachers. Furthermore, modularity was shown to be a significant predictor of stroke (Pishghadam et al., 2015). That is, teachers who see intelligence as non-influential in language learning provide their students with more stroke. In other words, Pishghadam (2014) demonstrated that modulars care more about their students, know their names and distribute their eye contact equally.

All these points reveal the importance of positive stroke in educational settings. Although it has been revealed that learners will achieve higher levels of performance in an environment which is stroke-rich (Freedman, 1993), seemingly few studies have examined stroke as a good feature of teachers and its relationship with teacher success to bridge the gap.

\section{Femininity/Masculinity}

Gender identity, as one of the most basic components of personality, is defined as a person's perception of his/her own degree of maleness and femaleness regardless of his/ her biological sex (Bem, 1974). Culturally determined roles of men and women in a society are called masculine and feminine roles which are only partly determined by biological constraints (Hofstede et al., 2010). While men are generally supposed to be more assertive, competitive, and fully focused on material success in various societies, women are supposed to be more modest, caring and concerned with the quality of life (Hofstede, 1980). These characteristics are the results of a combination of biological, cultural and social influences (Stets \& Burke, 2000). They stated that roots of femininity and masculinity are social (one's gender) rather than biological (one's sex). What being female or male means (e.g., brave or emotional, dominant or passive) is determined by the social and cultural conditions (Hofstede et al., 2010). Gender role socialisation which occurs in the family, religious institutions, educational settings, mass media and peer networks may cause one's femininity or masculinity (Hofstede et al., 2010; Katz, 1986; Sifuna et al., 2006; Stromquist, 2007).

Contrary to the traditional view, gender identity is not limited to a dichotomy. Constantinople (1973) challenged the mutually exclusive view of gender. She argued that masculinity and femininity should not be represented as two opposite ends of a single scale, rather, they are in fact two distinct dimensions on which individuals could be measured. Hence, a person could be high or low in both masculinity and femininity at the same time. The result of such a two-dimensional concept of gender was the coinage of the term androgyny (from "andro" meaning male and "gyn" referring to female) by Bem (1974) to describe the gender identity of those who have both masculine and feminine qualities, depending on which behaviors best suit a particular situation. In addition, while those who did not fit within the masculinefeminine divide were commonly labelled as deviant and ostracised (Chege \& Sifuna, 2006), Bem (1974) boldly presented androgyny as an advantage which can cause greater behavioral flexibility.

Femininity/masculinity of each culture, as an important dimension of the national cultures, has its impact on education (Hofstede et al., 2010). Some of the manifestations of femininity and masculinity in education are discussed by Hofstede et al. (2010). Excellence is a masculine concept and awards for excellence, for teachers or students, are not so common in feminine cultures. The average student is considered to be the norm in the more feminine cultures, while the best student is considered the norm in the more masculine cultures. Evaluating criteria, for both the teachers and students, are different in feminine and masculine cultures. In masculine education, teachers' intelligence and academic reputation are praised, and teachers are more likely to be tough, assertive and ego-oriented. Moreover, there is a competitive atmosphere in class in which students' academic performance is stressed in masculine education. On the other hand, teachers' friendliness, social capacities and students' social adaptation are the most important factors in feminine cultures. In addition, mistakes are generally treated as an integral part of learning in feminine education, whereas right answer and accuracy are highly valued in masculine cultures.

In a recent study, Pishghadam, Saboori et al. (2016) constructed and validated a Masculinity/Femininity Scale (MFS) and revealed and compared the dominant gender identity of language teachers in Iran. Findings of this study indicated the dominant femininity of English teachers and masculinity of Arabic and Persian teachers.

In another study conducted by Ozkan Lajunen (2005) in Turkey, TEFL (Teaching English as a Foreign Language) students' personality traits were investigated in their first and last years of university education, and it was shown that while male students' masculine traits remained unchanged at the end of investigation, female students lost their femininity and their feminine traits were changed to the masculine ones.

Moreover, Kizilaslan Diktas (2011) investigated and compared the gender role perceptions of senior student teachers. Results indicated that females scored 
significantly higher on femininity than their male peers did. Similarly, males scored significantly higher on masculinity than their female peers did. These findings suggest that student teachers still have a traditional perspective on gender role, and that university education does not generally enable student teachers to question the prescribed gender roles.

Whereas convergent empirical evidence reveals that gender identity is an influential factor in the educational contexts (e.g., Chapman, 2000; Francis, 2000; Paechter, 2001), that it is also related to academic performance (e.g., Marrs et al., 2012; Paver \& Gammie, 2005; Wheeless \& Potorti, 1989), researchers have hardly ever probed into the perceived notions and implications of teachers' gender identity. This study aims at investigating this issue because it could be of particular significance in the educational contexts. It is noteworthy that here teachers' gender identity was examined, not from the teachers' point of view, but, just as the other two variables, from their learners' perception.

\section{PURPOSE OF THE STUDY}

This study sought to probe into the relationships between stroke, teacher gender identity and teacher success. In particular, it aimed to examine the predictive power of the variables of stroke and teacher gender identity in teacher success. Insight into the predictors of teacher success will guide to improve performances and this will, in turn, guarantee the effectiveness of teachers in future. Accordingly, this study sought to answer the following questions:

1. Is there any significant relationship between teacher success, gender identity and stroke?

2. Can teacher success be predicted by teacher's gender identity and stroke?

\section{METHOD}

\section{Participants}

A total number of 287 Iranian EFL learners took part in this study to rate $23 \mathrm{EFL}$ teachers in a number of private language institutes in Mashhad, Iran. Participants included 69 males and 218 female learners, aged above 18. They came from different socioeconomic backgrounds and their language proficiency varied from elementary to advanced levels. Moreover, the selection of participants was based on convenience sampling and participation was entirely voluntary.

\section{Instrumentation}

To collect the required information, three instruments were administered to the sample: Characteristics of Successful Iranian EFL Teachers Scale (Moafian \& Pishghadam, 2009) Masculinity/Femininity Scale (Pishghadam, Saboori et al., 2016), and Student Stroke Scale (Pishghadam \& Khajavi, 2014).

\section{Characteristics of Successful Iranian EFL Teachers Scale}

To evaluate language teachers' performance and success in language teaching, Characteristics of Successful Iranian EFL Teachers Scale (TSS) designed by Moafian \& Pishghadam (2009) was employed. This scale was in Persian and included 47 items, each followed by a 5 -point Likert scale ranging from 'strongly agree' to 'strongly disagree'. It measured the twelve following factors: Teaching accountability, Interpersonal relationships, Attention to all, Examination, Commitment, Learning boosters, Creating a sense of competence, Teaching boosters, Physical and emotional acceptance, Empathy, Class attendance and Dynamism. The results of reliability analysis exhibited a high total reliability for TSS $($ Cronbach alpha $=0.94)$. Its reliability in the present study was 0.97 .

\section{Masculinity/Femininity Scale}

To obtain measures of the teachers' gender identity through student evaluation, Masculinity/Femininity Scale (MFS) designed by Pishghadam, Saboori et al. (2016) was utilised. It was in Persian and included 30 adjectives among which the students had to choose the ones which best described their EFL teacher. Factors measured by MFS were Femininity, Masculinity and Androgyny, and the Cronbach Alpha estimated the reliability of all the items as 0.92 . In the present study, all of the three factors yielded good reliability estimates ranging from 0.65 to 0.74 .

\section{Student Stroke Scale}

To assess the stroke given to EFL learners by their teachers, Student Stroke Scale (SSS) developed in Persian by Pishghadam \& Khajavy (2014) was used. It was a 5-point Likert scale ranging from 1 (never) to 5 (always) and included 20 items which were indicators of different types of stroke. The main characteristics of the stroke are recognition by other people and also providing feedback for the other people. Recognition and providing feedback can be verbal or non-verbal, positive or negative. Moreover, factors of this scale were Verbal stroke, Non- 
verbal stroke, Valuing and Classroom activities. All these factors yielded good reliability estimates ranging from 0.75 to 0.89 . Estimated reliability of the whole items of this scale was 0.78 in this study.

\section{Procedure}

The three aforementioned scales were distributed among the participants simultaneously. Through answering the items of these scales, EFL learners evaluated their teachers' performances, gender identity and strokes. For the purpose of receiving a reliable evaluation by the learners, the researchers assured the learners that their views would be confidential. After collecting the data, Pearson product-moment correlation formula was used to examine the relationships between the intended variables. Next, the predictive power of femininity, androgyny, masculinity and stroke in teacher success was assessed through Path Analysis. In order to analyse the data, AMOS (version 20) and SPSS(version18) were utilised. Moreover, to estimate the reliability of the employed scales, Cronbach alpha was used.

\section{RESULTS}

Table 1 shows the descriptive statistics for and correlations among the factors related to the three administered instruments: MFS, TSS, and SSS.

To examine any significant relationships between teacher success, gender identity and stroke, Pearson product-moment correlation formula was used. As Table 1 shows, teacher success is significantly and positively correlated to femininity $(\mathrm{r}=0.37, \mathrm{p}<0.05)$, masculinity $(\mathrm{r}=0.30, \mathrm{p}<0.05)$, androgyny $(\mathrm{r}=0.46, \mathrm{p}<0.05)$, and stroke $(\mathrm{r}=0.47, \mathrm{p}<0.05)$. The highest correlation is shown between stroke and androgyny.

Moreover, stroke was significantly and positively correlated to femininity $(r=0.24, \mathrm{p}<0.05)$, masculinity $(\mathrm{r}=0.26, \mathrm{p}<0.05)$ and androgyny $(\mathrm{r}=0.19 . \mathrm{p}<0.05)$. It has the highest correlations with masculinity and femininity, respectively.

\section{Path Analysis}

Path Analysis was used to examine the predictive power of femininity, androgyny, masculinity and stroke in teachers' success. In the proposed model, femininity, androgyny and masculinity predicted stroke and stroke in turn predicted teacher success. Femininity, androgyny and masculinity were also proposed to predict teacher success.

The final model can be seen in Figure 1. To check the acceptability of the model, goodness of fit indices were used. In this study, $\chi 2 / \mathrm{df}$, GFI, CFI, TLI, and RMSEA were used (Table 2). To have a fit model, $\chi 2 / \mathrm{df}$ should be less than 3, GFI, CFI, TLI should be more than 0.90, and RMSEA should be less than 0.08 . It showed good fit to the data $(\chi 2 / \mathrm{df}=0.12, \mathrm{GFI}=0.99, \mathrm{CFI}=1.00, \mathrm{TLI}=1.00$, and RMSEA $=0.01)$. Three paths were not significant and were removed. These paths included the paths from femininity and masculinity to teacher success, and the path from androgyny to stroke. As Figure 1 indicates, femininity $(\beta=0.13, p<0.05)$ and masculinity $(\beta=0.21$, $\mathrm{p}<0.05$ ) were positive predictors of stroke. Also, stroke $(\beta=0.49, \mathrm{p}<0.05)$ and androgyny $(\beta=0.39, \mathrm{p}<0.05)$ were positive predictors of teacher success.

Table 1: Descriptive statistics and correlations among the subscales of gender identity, Teacher Success and Stroke

\begin{tabular}{llrrrr}
\hline & & $\mathrm{M}$ & $(\mathrm{SD})$ & Teacher Success & Stroke \\
\hline TSS & Teacher Success & 195.91 & $(24.68)$ & 1.00 & ${ }^{*} 0.47$ \\
MFS & Femininity & 4.51 & $(2.23)$ & ${ }^{*} 0.37$ & ${ }^{*} 0.24$ \\
& Masculinity & 5.02 & $(2.05)$ & ${ }^{*} 0.30$ & ${ }^{*} 0.26$ \\
& Androgyny & 7.11 & $(2.06)$ & ${ }^{*} 0.46$ & 0.19 \\
SSS & Stroke & 62.96 & $(10.943)$ & ${ }^{*} 0.47$ & 1.00 \\
\hline
\end{tabular}

Table 2: Goodness of Fit Indices

\begin{tabular}{rrrrrr}
\hline & $\chi^{2 / \mathrm{df}}$ & GFI & CFI & TLI & RMSEA \\
\hline Model & 0.12 & 0.99 & 1.00 & 1.00 & 0.01 \\
\hline
\end{tabular}




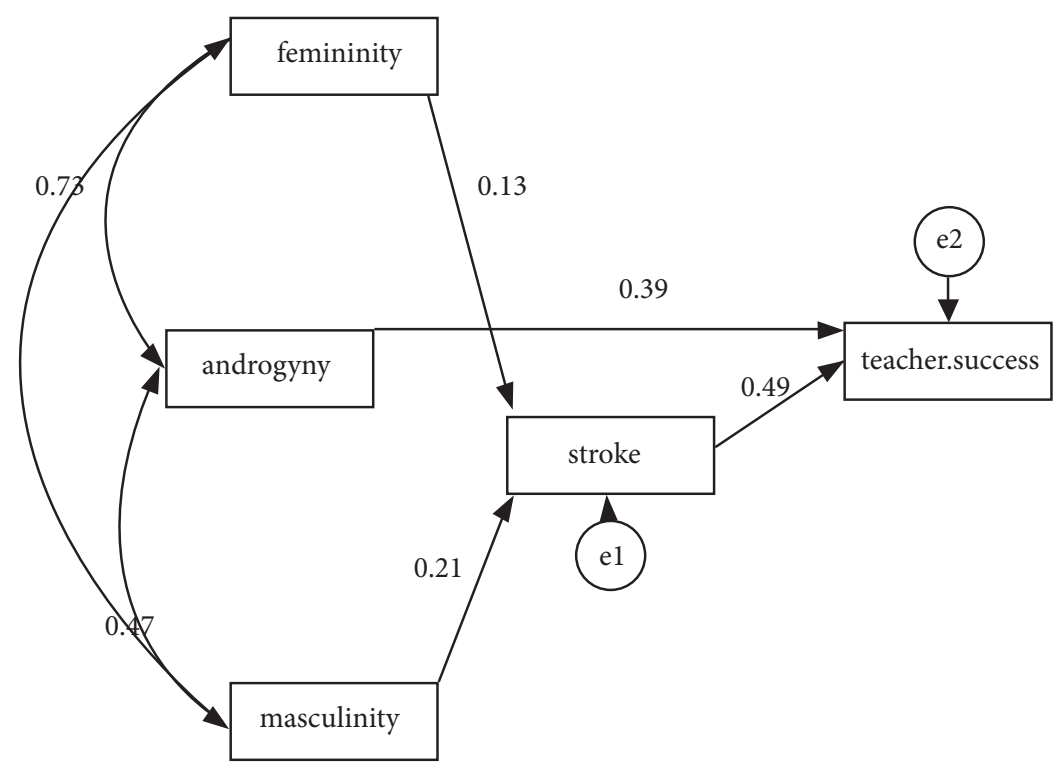

Figure 1: Path Analysis of teachers' Gender Identity, Stroke \& Teacher Success

\section{DISCUSSION}

The present study had two goals. The first one was to investigate whether there are significant relationships among teacher success, gender identity and stroke. The results showed that teacher success was significantly correlated with femininity, masculinity, androgyny and stroke. As already indicated, teacher success had the highest correlations with stroke and androgyny, respectively. It was also shown that stroke was highly correlated with masculinity and femininity. That is, while stroke and androgyny were directly related to EFL teachers' success, femininity and masculinity were indirectly (through provoking strokes) related to it. This finding was further confirmed by those of the path analysis discussed below.

The second goal of this study was to examine the predictive power of teacher gender identity and stroke in teachers' success. Regarding this goal, the present study made two notable predictions with an eye to the relationships among the aforementioned variables. The first prediction of the Path Analysis denoted that feminine and masculine gender identity of the teachers were significant predictors of the stroke given to the learners, meaning that EFL teachers are more likely to give strokes to their learners if they have dominant masculine or feminine qualities.

There are some lines of explanation for this finding. First, the femininity of the teachers who care more about their students and provide them with more stroke can be justified through their nurturing roles which necessitate their tenderness, modesty and care (Hofstede et al., 2010). In the same vein, stroke is also one of the important components of teacher care (Pishghadam et al., 2015). Teacher care refers to those practices conducted by the teachers to build up rapport and a positive relationship with their students (Rogers \& Webb, 1991). Accordingly, feminine qualities of the teachers promote their friendliness (Hofstede et al., 2010), and hence, it is predicted that more stroke and care will be provided for the students. In addition, teaching has been conceptualised as a "culture of care" (Nias, 1999: p. 66), and the teachers spend long hours with their learners and their care often extends beyond the call of duty (Acker, 1995). Findings of this study confirm Vogt (2002) who revealed that female teachers who possess more feminine qualities can develop strong affective relationships with their learners (Vogt, 2002) and thus, provide them with more care. Noddings (1984) and Gilligan (1982) also indicated that female teachers, who are more feminine, are more caring than male teachers. As for the role of masculinity, it can be argued that since the culture of Iran is dominantly collective, hierarchical and masculinebased (Hofstede, 1983), EFL teachers who possess more masculine qualities provide their students with more strokes and are more comfortable in distributing their eye contact equally and caring more about their students.

The second noteworthy prediction provided by the Path Analysis was that stroke and androgyny were significant predictors of teacher success. That is, EFL teachers with dominant androgynous qualities (e.g., happy, honest, reliable and funny) who provide their learners with more stroke are more likely to succeed in their teaching practices than fellow colleagues. 
This finding confirmed Yazdanpour (2015), indicating that there is a negative relationship between teacher stroke and teacher burnout. According to Yazdanpour (2015), EFL teachers who give more strokes to their students would be less burned-out than their counterparts who ignore the value of strokes. Since teacher burnout is a major social dysfunction which is not only limited to the teacher's own wellbeing but might have repercussions for the teaching-learning processes in which he or she is immersed (Saboori \& Pishghadam, 2016). Less danger of teacher burnout might guarantee more success for the EFL teachers in their teaching practices in the educational contexts.

Furthermore, stroke prediction can be justified considering the fact that EFL teachers who provide the learners with more stroke can help them achieve higher levels of performance (Freedman, 1993; Kusluvan, 2003), and improve their intrinsic and extrinsic motivation (Pishghadam \& Khajavy, 2014), and are, thus, more likely to experience a successful teaching practice. In other words, stroke, as an important component of teacher care (Pishghadam et al., 2015) plays an influential role in teacher success. Teacher care has been associated with a number of positive outcomes including higher attendance, increased time spent studying, improved academic achievement, lower anxiety and lower dropout rate (Bieg et al., 2013; Foster, 2008).

Moreover, the situation of language teaching reveals that communicative skills and functional aspects of language are mostly prominent in language institutes, so that teacher's rapport, relationship with and care for learners are considered to be necessary for these classes (Saboori \& Pishghadam, 2016). As a result, EFL teachers who possess this asset (stroke) can better fulfill the demands of the job and are consequently more likely to feel successful in their work. Since Iranian EFL teachers got the second rank, after Arabic teachers, in providing students with strokes (Irajzad, 2015), and stroke, in the present study, is also shown to be a significant predictor of teacher success, it seems that Iranian EFL teachers are equipped with one of the necessary qualities of successful teachers.

As for the role of androgyny in predicting teacher success, these findings seem to contradict those of Pishghadam, Shayesteh et al. (2016) in which English school teachers were shown to be of dominant feminine qualities. While they indicated, from the Iranian students' perspective, that the teachers were either masculine or feminine and none was found to be androgynous, this study illustrates the significance of androgynous gender identityof EFL teachers in the Iranian context with regard to teacher success in the private language institutes. This could, in turn, result from the differences of formal and informal contexts of education. Different classroom factors, such as the textbooks, the methodology applied, the evaluation system (Rahimi et al., 2008), greater autonomy (Jimenez \& Lockhead, 1995), and more democratic teaching and learning context of private language institutes compared to schools (Pazhouhesh, 2014) might illustrate this contrast well. According to Pazhouhesh (2014), while classes in public schools are predominantly teacher-fronted, language institute learners have greater degrees of control over content, grouping patterns, and overall learning roles. On the other hand, language institute teachers seem to adopt a more liberal role by employing more practices of their own choices (Pazhouhesh, 2014).

The findings of the present study contribute to the current literature on EFL teacher success in several ways. A better understanding of the factors that are associated with and predict success in EFL teachers can inform efforts to increase skills in teachers. As Gourneau (2005: p.1) stated that "effective attitudes and actions employed by teachers can ultimately make positive differences on the lives of their students", the first and the most important outcome of the present study is to make changes in teachers' performances and provide them with effective attitudes that can cause better learning outcomes in their students.

Furthermore, given the significance of pre-service training in reinforcing or changing belief systems (Koc, 2013), these findings should be utilised in teacher pre- and in-service training programmes to satisfy the practical needs of EFL teachers. As insufficiency of effective teachers can harm learning to a great extent, knowledge of the factors which might cause teacher success seems to be necessary for teacher trainers. Expecting efficient educational processes is impossible unless the teacher is qualified enough (Sahan, 2009). When the teachers are trained well, they can successfully impart knowledge, wisdom, self-efficacy, creativity and all that is required for the students. Finally, the outcomes of this study can be used by policy makers, educational planners, and administrators. According to Darling-Hammond (2010), policy makers and practitioners have concluded that one of the most promising strategies for improving educational outcomes is the improvement of teacher quality. Educational systems can use the outcomes of this study to benefit from improvements in the quality of education besides saving time and money.

Results of this study should be interpreted in light of some limitations. First of all, the findings are contextualied by an Iranian sample of teachers and students. Also, it was carried out only in private language 
institutes, which is an informal setting, and so the results may not be generalisable to formal ones, such as public schools. Furthermore, the researcher acknowledges that it would be much more informative if teachers of other subjects were taken into account. More investigations need to be carried out to see whether similar results might be obtained from other educational settings and subject areas. Furthermore, as the convenience sampling is used, it is suggested to interpret the results with great caution. Moreover, future research could replicate this study by measuring teachers' gender identity as perceived by the teachers themselves rather than by their learners. In addition, such factors as age, gender, proficiency level of learners and experience rate of teachers were not controlled for in this study. Future research can examine whether controlling for these variables can yield different results. Finally, the only method applied for the data collection was survey. In order to conduct a more comprehensive examination of teacher success, future studies need to collect data through other methods such as interview and observation.

\section{ACKNOWLEDGEMENT}

The authors wish to express their sincere gratitude to the editor and anonymous reviewers of this manuscript who assisted in fine-tuning the paper. The authors also extend their special thanks to the participants who willingly took part in this study.

\section{REFERENCES}

Acker, S. (1995) Carry on caring: the work of women teachers, British Journal of Sociology of Education, 16, pp: 21-36.

DOI: https://doi.org/10.1080/0142569950160102

Bem, S. L. (1974) The measurement of psychological androgyny, Journal of Consulting and Clinical Psychology, 42, pp: 155-162.

DOI: https://doi.org/10.1037/h0036215

Berne, E. (1988) Games people play, New York, NY: Grove.

Bieg, S., Rickelman, R. J., Jones, J. P. \& Mittag, W. (2013) The role of teachers' care and self-determined motivation in working with students in Germany and the United States, International Journal of Educational Research, 60, pp: 27-37.

DOI: https://doi.org/10.1016/j.ijer.2013.04.002

Chapman, A. (2000) The difference it has made: The impact of the women's movement on education, Independent School, 60(1), pp: 20-30.

Chege, F. N. \& Sifuna, D. N. (2006) Girls' and women's education in Kenya: Gender perspectives and trends, Nairobi: UNESCO.
Constantinople, A. (1973) Masculinity-femininity: An exception to a famous dictum, Psychological Bulletin, 80, pp: 389-407.

DOI: https://doi.org/10.1037/h0035334

Darling-Hammond, L. (2010) Teacher education and the American future, Journal of Teacher Education, 61(1-2), pp: $35-47$.

DOI: https://doi.org/10.1177/0022487109348024

Elizabeth, C. L., May, C. M. \& Chee, P. K. (2007) Building a model to define the concept of teacher success in Hong Kong, Teaching and Teacher Education, 24, pp: 623-634.

DOI: https://doi.org/10.1016/j.tate.2007.09.007

Foster, K. C. (2008). The transformative potential of teacher care as described by students in a higher education access initiative, Education and Urban Society, 41(1), 104-126.

DOI: https://doi.org/10.1177/0013124508321591

Francis, B. (2000) Boys, girls and achievement. Addressing the classroom issues, London: Routledge Falmer.

Freedman, M. (1993) The kindness of strangers: Adult mentors, urban youth and the new volunteerism, San Fransisco: JosseyBass Publishers.

Gilligan, C. (1982) In a different voice, Cambridge, MA: Harvard University Press.

Gourneau, B. (2005) Five attitudes of effective teachers: Implications for teacher training, Essays in Education, 13, pp: $1-8$.

Harris, J. (1994) English sound structure, Oxford: Blackwell.

Hashemi, M. (2008) On the role of teachers' emotional intelligence on their pedagogical success (Unpublished master's thesis), Tehran: AllameTabataba'I University.

Hofstede, G. (1980) Culture's consequences: International differences in work-related values, Beverly Hills, CA: Sage.

Hofstede, G., Hofstede, G. J. \& Minkov, M. (2010) Cultures and organizations: Software of the mind, $3^{\text {rd }}$ ed., New York: McGraw-Hill.

DOI: https://doi.org/10.1016/j.ijer.2013.04.002

Irajzad, F., Pishghadam, R. \& Shahriari, H. (2017) Examining the stroking behavior of English, Persian and Arabic school teachers in Iran: A mixed-methods study, International Journal of Instruction, 10(2), pp: 219-236.

DOI: https://doi.org/10.12973/iji.2017.10114a

Irajzad, F. (2015) Stroke analysis of Persian, Arabic, and English teachers: A case of female teachers in the context of Iranian schools (Unpublished master's thesis), Mashhad: Ferdowsi University. 
Jimenez, E. \& Lockheed, M. E. (1995) Public and private secondary education in developing countries: A comparative study, World Bank Discussion Paper No. 309, Washington, DC: World Bank Publications.

Katz, P. A. (1986) Gender Identity: Development and consequences, In Ashmore, R. D. \& Del Boca, F. K. (eds) The social psychology of female-male relations: A critical analysis of central concepts, pp: 21-67, New York: Academic Press.

DOI: https://doi.org/10.1016/B978-0-12-065280-8.50007-5

Kizilaslan, I. \& Diktaş, I. Ö. (2011) The role of university education in changing the gender role perceptions of Turkish ELT student teachers, International Online Journal of Educational Sciences, 3(2), pp: 510-525.

Koc, M. (2013) Student teachers' conceptions of technology: A metaphor analysis, Computers \& Education, 68, pp: 1-8.

DOI: https://doi.org/10.1016/j.compedu.2013.04.024

Kusluvan, S. (2003) Managing employee attitudes and behaviors in the tourism and hospitality industry, New York: Nova Publishers.

Marrs, H., Sigler, E. \& Brammer, R. (2012) Gender, masculinity, femininity, and help seeking in college, Masculinities and Social Change, 1(3), pp: 267-292.

Moafian, F. \& Pishghadam, R. (2009) Construct validation of a questionnaire on characteristics of successful Iranian EFL teachers, Pazhuhesh-e ZabanhayeKhareji Journal, 54, pp: 127-142.

Moore, W. P. \& Esselman, M. E. (1992) Teacher efficacy, empowerment, and a focused instructional climate: Does student achievement benefit?, Paper presented at the Annual Meeting of the American Educational Research Association, San Francisco.

Muijs, R. D. \& Rejnolds, D. (2001) Teachers' beliefs and behaviors: What really matters?, Journal of Classroom Interaction, 37, pp: 3-15.

Nias, J. (1999) Primary teaching as a culture of care, In Prosser, J. (ed.) School culture, pp: 66-81, London: Paul Chapman Pub. DOI: https://doi.org/10.4135/9781446219362.n5

Noddings, N. (1984) Caring. A feminine approach to ethics and moral education, Berkley, CA: University of California Press.

Ozkan, T. \& Lajunen, T. (2005) Masculinity, femininity, and the Bem sex role inventory in Turkey, Sex Roles, 52(1-2), pp: 103-110.

DOI: https://doi.org/10.1007/s11199-005-1197-4

Paechter, C. (2001) Using poststructuralist ideas in gender theory and research, In Francis, B. \& Skelton, C. (ed) Investigating gender: Contemporary perspectives in education, pp: 41-51, Buckingham: Open University Press.
Papanastasiou, E. (1999) Teacher evaluation (Unpublished manuscript), Michigan State University, East Lansing.

Paver, B. \& Gammie, E. (2005) Constructed gender, approach to learning and academic performance, Accounting Education: An International Journal, 14(4), pp: 427-444.

Pazhouhesh, M. (2014) Teaching English in state-run and private language schools in Iran: Approaches, designs and procedures, International Journal of Language Learning and Applied Linguistics, 5(1), pp: 43-56.

Pierson, J. (2003) Tackling social exclusion, Routledge.

Pishghadam, R. \& Khajavy, G. H. (2014) Development and validation of the Student Stroke Scale and examining its relation with academic motivation, Studies in Educational Evaluation, 43, pp: 109-114.

DOI: https://doi.org/10.1016/j.stueduc.2014.03.004

Pishghadam, R. (2014) Social conceptions of intelligence and their influence on English language teacher care. Paper presented at the 2014 Annual International Conference on LSP and Specialized Translation Skills Training, $8^{\text {th }}$ April 2014.

Pishghadam, R. Moafian, F. (2008) The role of Iranian EFL teachers' multiple intelligences in their success in language teaching at high schools, Pazhuhesh-e ZabanhayeKhareji Journal, 42, pp: 5-22.

Pishghadam, R., Baghaei, P. \& Shahriari, H. (2011) Development and validation of an English language teacher competency test using Item Response Theory, The International Journal of Educational and Psychological Assessment, 8(9), pp: 54-68.

Pishghadam, R., GhorbaniNejad, T. \& Shayesteh, Sh. (2012) Creativity and its relationship with teacher success, BELTBrazilian English Language Teaching Journal, 3(2), pp: 204216.

Pishghadam, R., Golparvar, S. E. \& Khajavy, G. H. (2013) The role of narrative intelligence in English language teaching, major and gender, Porta Linguarum, 19(1), pp: 59-70.

Pishghadam, R., NajiMeidani, E. \& Khajavy, G. H. (2015) Language teachers' conceptions of intelligence and their roles in teacher care and teacher feedback, Australian Journal of Teacher Education, 40(1), pp: 60-82.

DOI: https://doi.org/10.14221/ajte.2015v40n1.4

Pishghadam, R., Saboori, F., Samavarchi, L. \& Hassanzadeh, T. (2016) Examining the gender identity of language teachers using a masculinity-femininity scale: A case from Iran, Issues in Educational Research, 26(1), pp: 131-146.

Pishghadam, R., Shayesteh, Sh. \& Rahmani, S. (2016) Contextualization-emotionalization interface: A case of teacher success, International and Multidisciplinary Journal of Social Sciences, 5(2), pp: 97-127.

DOI: https://doi.org/10.17583/rimcis.2016.1907 
Pishghadam, R., Shayesteh, Sh. \& Shapoori, M. (2011) Validation of an NLP scale and its relationship with teacher success in high schools, Journal of Language Teaching and Research, 2(4), pp: 909-917.

DOI: https://doi.org/10.4304/jltr.2.4.909-917

Rahimi, M., Riazi, A. \& Saif, S. (2008) An investigation into the factors affecting the use of language learning strategies by Persian EFL learners, Canadian Journal of Applied Linguistics/ Revue canadienne de linguistiqueappliquée, 11(2), pp: 31-60.

Richardson, V. (2001) Handbook of research on teaching, $4^{\text {th }}$ Ed., Washington: American Educational Research Association.

Rogers, D. \& Webb, J. (1991) The ethic of caring in teacher education, Journal of Teacher Education, 42(3), 173-181.

DOI: https://doi.org/10.1177/002248719104200303

Saboori, F. \& Pishghadam, R. (2016) English language teachers' burnout within the cultural dimensions framework, The Asia-Pacific Education Researcher, 25(4), pp: 677-687.

DOI: https://doi.org/10.1007/s40299-016-0297-y

Sahan, H. H. (2009) Teachers' changing roles and their selfevaluation regarding roles expected of them by the renewed curricula, Procedia-Social and Behavioral Sciences, 1, pp: 2738-2747.

DOI: https://doi.org/10.1016/j.sbspro.2009.01.486

Shirai, S. (2006) How transactional analysis can be used in terminal care, International Congress Series, 1278, pp: 179184.

DOI: https://doi.org/10.1016/j.ics.2005.12.052

Sifuna, D. N., Chege F. N. \& Oanda, I. O. (2006) Themes in the study of the foundations of education, Nairobi: Jomo Kenyatta Foundation.
Solomon, C. (2003) Transactional analysis theory: Basics, Transactional Analysis Journal, 33, pp: 15-22.

DOI: https://doi.org/10.1177/036215370303300103

Stets, J. E. \& Burke, P. J. (2000) Identity theory and social identity theory, Social Psychology Quarterly, 63 (3), pp: 224237.

DOI: https://doi.org/10.2307/2695870

Stewart, I. \& Joines, V. (1987) TA today: A new introduction to transactional analysis, Nottingham: Life space.

Stromquist, N. P. (2007) The gender socialization process in schools: A cross-national comparison, Background paper prepared for the Education for All Global Monitoring Report 2008 Education for All by 2015: will we make it?, UNESCO.

Vogt, F. (2002) A caring teacher: Explorations into primary school teachers' professional identity and ethic of care, Gender and Education, 14(3), pp: 251-264.

DOI: https://doi.org/10.1080/0954025022000010712

Watchel, P. L. (1980) Transference, schema, and assimilation: The relevance of Piaget to the psychoanalytic theory of transference, Annual of Psychology, 8, pp: 59-76.

Wheeless, V. \& Potorti, P. (1989) Student assessment of teacher masculinity and femininity: A test of the sex role congruency hypothesis on student attitudes toward learning, Journal of Educational Psychology, 81(2), pp: 259-62.

DOI: https://doi.org/10.1037/0022-0663.81.2.259

Yazdanpour, H. (2015) Constructing and validating a teacher stoke scale and examining its relationship with burnout (Unpublished master's thesis), Mashhad: Ferdowsi University. 